\title{
Silica Gels from Coal Fly Ash as Methylene Blue Adsorbent: Isotherm and Kinetic Studies
}

\author{
Yudi Aris Sulistiyo*), Nida Andriana, Bambang Piluharto, Z. Zulfikar \\ Chemistry Department, Faculty of Mathematics and Natural Science, \\ University of Jember, Indonesia
}

Received: $13^{\text {rd }}$ November 2016; Revised: $18^{\text {th }}$ February 2017; Accepted: $19^{\text {th }}$ February 2017

\begin{abstract}
A lot of dye pollutants were released in the aquatic environment as waste from industrial coloring process. This research aimed to study silica gels (SG) as a potential adsorbent to remove the dyes. The SG can be synthesized from coal fly ash (FA), which is industrial solid waste rarely utilized, using the sol-gel method. Its properties were then characterized by FTIR, XRD, SEM, and isothermal ads-des $\mathrm{N}_{2}$. As a result, FTIR spectra and XRD diffractogram exhibited the successfully SG synthesized from FA with the amorphous structure. The image analysis using SEM demonstrated that SG particles are spherical. The isotherm type, based on isotherm ads-des $\mathrm{N}_{2}$, is type II without hysteresis loop which represents the nonporous material SG with the surface area and pore diameter of $25.977 \mathrm{~m}^{2} / \mathrm{g}$ and 1.52 $\mathrm{nm}$, respectively. The adsorption capacity performance of SG to remove methylene blue (MB) as a basic dye is $62.70 \%$ which is higher than FA, following Langmuir isotherm adsorption model. The kinetics of adsorption rate of SG are based on the pseudo second order models accelerated by 3.37 times faster than FA. Copyright (C) 2017 BCREC Group. All rights reserved
\end{abstract}

Keywords: Adsorption isotherms; Coal fly ash; Kinetics; Methylene blue dyes; Silica gel

How to Cite: Sulistiyo, Y.A., Andriana, N., Piluharto, B., Zulfikar, Z. (2017). Silica Gels from Coal Fly Ash as Methylene Blue Adsorbent: Isotherm and Kinetic Studies. Bulletin of Chemical Reaction Engineering \& Catalysis, 12 (2): 263-272 (doi:10.9767/bcrec.12.2.766.263-272)

Permalink/DOI: http://dx.doi.org/10.9767/bcrec.12.2.766.263-272

\section{Introduction}

The production of the dye is up to $7 \times 10^{5}$ tons/year and consists of 10,000 kinds [1]. The dyes are used in some manufacturers, such as textiles, printings, cosmetics, and food dyes industries. Approximately, $50 \%$ of the dyes are released to the environment as pollutants, because of low interaction between fibers and dyes [2]. Therefore, some pollutants in the aquatic environment can be up to $3.5 \times 10^{5}$ tons /year. The waste water from the industry containing inorganic dye is one of the pollutants that are

* Corresponding Author.

E-mail: yudi.fmipa@unej.ac.id (Sulistyo, Y.A.) difficult to degrade. This dye is easy to bind with other compounds, has a slow biodegradation rate, and has a high level of color (chroma) [3]. This high concentration of inorganic dyes in the environment will decrease the ecosystem quality because it inhibits sunlight and disrupts biological processes in water [4]. In addition, it is highly toxic and may damage the landscape of the affected environment.

The methods that have been developed for solving problems related to dyes are adsorption [5], coagulation and oxidation [6], photodegradation [7], biodegradation [8], and membrane filtration [9]. However, adsorption appears to be the most feasible method. It is because the adsorption method is easy to imple- 
ment, low-cost technology, effective, wide $\mathrm{pH}$ tolerance and does not create new problems to the environment (environmentally friendly) [10]. The adsorption process requires the adsorbent to be easily separated from its adsorbate, having a high surface area, large pores, and good chemical and thermal stability. The common materials used in adsorption are zeolites, activated carbon, metal organic frameworks, metal oxide, and other porous materials. Some porous materials from industrial solid waste are less used in research focusing on removal of the dyes.

Among the industrial solid wastes used to remove methylene blue dye (MB), fly ash is potential as the material for adsorbent [11]. Fly ash can be found in the coal combustion process along with bottom ash approximately in the amount of $80 \%$ and $20 \%$, respectively. Moreover, fly ash contains chemical compounds such as $\mathrm{SiO}_{2} 64.97 \% ; \mathrm{Al}_{2} \mathrm{O}_{3} 26.64 \% ; \mathrm{Fe}_{2} \mathrm{O}_{3} 5.69 \%$; $\mathrm{CaO} 0.33 \%$; and $\mathrm{MgO} 0.85 \%$ [12]. The adsorption capacity of the MB by raw fly ash varies from $12.7 \mathrm{mg} \cdot \mathrm{g}^{-1}$ [13], $4.60 \mathrm{mg} \cdot \mathrm{g}^{-1}$ [14], to 1.11 mg.g-1 [15]. Those sorption capacities are not sufficient to solve the MB problems, and therefore, it is necessary to find a more potential adsorbent based on FA.

Removal of metal oxide from FA to be Silica Gels (SG) by sol-gel method was found to increase the sorption capacity. Silica xerogels were produced from $\mathrm{SiO}_{2}$ extraction $91 \%$ from rice husk ash [16] and $99 \%$ of bagasse ash [17]. Silica gels offer the potential as an adsorbent for MB because it has silanol groups ( $\mathrm{Si}-\mathrm{OH}$ ) acting as the reactive surface that can adsorb both organic and inorganic pollutants [18]. Goschianska et al. [19] reported the adsorption capacity of ${ }_{L}$-phenylalanine using mesoporous silica gel, such as KIT-6 and SBA-15, were consecutively 69.38 and $64.26 \mathrm{mg} / \mathrm{g}$. Those adsorption capacities of mesoporous SG were higher than FA, and therefore that study shows the importance of isolating $\mathrm{SiO}_{2}$ from FA. To the author's knowledge, the potential use of SG that was isolated from FA as MB adsorbent is rarely investigated.

In this work, the aim of this research is to study the adsorption capacity of Methylene Blue as dyes by synthesized silica gel from fly ash. On the other hand, the using of fly ash as materials for silica gel will obtain many benefits such as to decrease the environmental problems that caused by the high amount of fly ash, to increase the economic value of fly ash and to overcome the Methylene Blue from industrial waste.

\section{Materials and Methods}

\subsection{Materials}

Materials used in this research were $\mathrm{NaOH}$ (Merck, 99 \%), $\mathrm{HCl}$ (Merck, $37 \%$ ), $\mathrm{H}_{2} \mathrm{SO}_{4}$ (Merck, 95-97 \%), Methylene Blue manufactured by Merck with molecular weight 319.86 g. $\mathrm{mol}^{-1}, \lambda_{\max } 664 \mathrm{~nm}$, and the structure depicted in Figure 1, fly ash from PT. IPMOMI Paiton Probolinggo, East Java, Indonesia.

\subsection{Sample preparation}

Sample preparation was prepared following Affandi et al. method [17]. The first step was the isolation of sodium silicate from FA with washing 10 grams of FA using $1 \mathrm{M} \mathrm{H}_{2} \mathrm{SO}_{4}$ for 2 h. The FA was added by $50 \mathrm{~mL} \mathrm{NaOH} 3 \mathrm{M}$ and heated with reflux condenser system. The mixture was filtered through a filter paper Whatman-41 to remove carbon residue. The filtrate solution that resulted was sodium silicate. Then, sodium silicate was acidified with 1 $\mathrm{M} \mathrm{HCl}$ until a $\mathrm{pH}$ 7. The mixtures were aged $18 \mathrm{~h}$. After aging, the slurry was filtered and washed with the deionized water. The powder was dried in oven $100{ }^{\circ} \mathrm{C} 4 \mathrm{~h}$.

\subsection{Characterization}

Synthesized Silica Gel was characterized by FT-IR, XRD, SEM, and Ads-Des $\mathrm{N}_{2}$. Characterization by FT-IR was analyzed in wavenumber ranges of 400-4000 $\mathrm{cm}^{-1}$. Characterization by X-ray diffraction was scanned at $2 \theta$ angle ranges of $5-50^{\circ}$ using $\mathrm{Cu}-\mathrm{Ka}$ radiation $(\lambda=1.54$ $\AA)$. Characterization by SEM was at 80,000 times magnification. Subsequently, the sample was measured surface area, pore size and volume using isothermal adsorption-desorption $\mathrm{N}_{2}$.

\subsection{Isothermal adsorption}

Isothermal adsorption was calculated based on the experimental results of the variation of the Methylene Blue concentration 25-500 mg. $\mathrm{L}^{-1}$ that adsorbed by $100 \mathrm{mg}$ adsorbent Fly

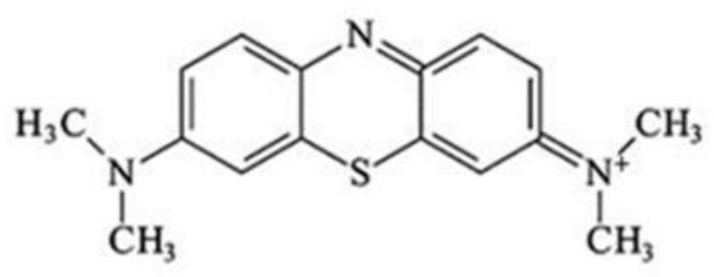

Figure 1. Chemical structure of Methylene Blue 
Ash and Silica Gels. The mixture was filtered, and the filtrate was measured as a residual concentration of Methylene Blue that is not absorbed by the adsorbent. Thus, the adsorption capacity data can be calculated by the following equation:

$$
q_{e}=\frac{V\left(C_{o}-C_{e}\right)}{M}
$$

where $q_{e}$ is the amount of Methylene Blue that absorbed per gram of adsorbent, $C_{0}$ and $C_{e}$ are the initial and at equilibrium (mg.L. ${ }^{-1)}$ Methylene Blue concentration, respectively. Based on the data adsorption capacity can be calculated the equilibrium adsorption isotherm using several models.

The Langmuir adsorption isotherm was developed as in Equation 2 [20]:

$$
\frac{1}{q_{e}}=\frac{1}{q_{\max }}+\left(\frac{1}{q_{m x} \cdot K_{L}}\right) \frac{1}{C_{e}}
$$

$q_{e}$ is the amount of adsorbate that adsorbed on the equilibrium condition (mg.g-1), $C_{e}$ is the equilibrium concentration of adsorbate (mg.L-1), $q_{\max }$ is the monolayer maximum adsorption capacity on the adsorbent (mg.g $\left.{ }^{-1}\right), K_{L}$ is Langmuir equilibrium constant that related to the free energy of adsorption (L.mg-1).

The Freundlich adsorption isotherm was developed as in Equation 3 [5]:

$\log q_{e}=\log K_{F}+\left(\frac{1}{n}\right) \log C_{e}$

$C_{e}$ is the equilibrium concentration of adsorbate (mg.L-1), $q_{e}$ is the amount of adsorbate that adsorbed per unit mass $\left(\mathrm{mg} \cdot \mathrm{g}^{-1}\right), K_{F}$ is the adsorption capacity of the adsorbent, $n$ is the Freundlich constants.

\subsection{Kinetics of adsorption}

The kinetics of adsorption was calculated based on experimental results of the variation of the interaction time $(15,30,45,60$, and 90 minutes) between $200 \mathrm{mg} . \mathrm{L}^{-1}$ of Methylene Blue and $10 \mathrm{mg}$ adsorbent Fly Ash and Silica Gels. The mixture was filtered, and the filtrate was measured as a residual concentration of MB that was not absorbed by the adsorbent. Based on these data, the studies of kinetics adsorption was calculated by pseudo-first-order, pseudo-second-order, Intra-particle and Elovich Diffusion Equations models.

Pseudo-first-order Model by isothermal Lagergren is typed as in Equation 4 [21]:

$$
\log \left(q_{e}-q_{t}\right)=\log q_{e}-\frac{k_{1}}{2.303} t
$$

$q_{t}$ and $q_{e}$ are the amounts of adsorbate adsorbed in time $t$ and equilibrium (mg.g $\left.{ }^{-1}\right), k_{1}$ is a constant pseudo-first-order $\left(\mathrm{min}^{-1}\right)$ and $t$ is the interaction time (min). Determining the value of $k_{1}$ may be determined by the plot between $\log \left(q_{e}-q_{t}\right)$ versus $t$.

Pseudo-second-order Model Ho and McKey [22] is typed in Equation 5:

$$
\frac{t}{q_{t}}=\frac{1}{k_{2} q_{e}^{2}}+\frac{1}{q_{e}} t
$$

$k_{2}$ is the Pseudo-second-order constant (g.mg${ }^{1}$. min $^{-1}$ ) that determined by plot $t / q_{t}$ versus $t$.

Intra-particle Diffusion Model [23] is typed as in Equation 6:

$$
q_{t}=k_{t} t^{1 / 2}+C
$$

where $k_{t}$ is the rate constant of intra-particle diffusion (mg.g ${ }^{-1} \cdot \mathrm{min}^{-1 / 2}$ ) and $C$ is an intercept which shows the relationship boundary layer thickness. The larger of the value of $C$ was the greater of the effect of the barrier layer.

Elovich Equation Model [21] is typed in Equation 7:

$$
q_{t}=\frac{1}{\beta} \ln (\alpha \beta)+\frac{1}{\beta} \ln t
$$

$a$ is the adsorption rate constant at first (mg. $\mathrm{g}^{-1} \cdot \mathrm{min}^{-1}$ ) and parameter $\beta$ is the relations of the surface that covered and chemisorption activation energy (g.mg-1). Values $a$ and $\beta$ can be calculated with a plot $q_{t}$ vs $\ln t$. Elovich Equation Model is often used when adsorption occurs on the heterogeneous surface.

\section{Results and Discussion}

\subsection{Characterization of adsorbent}

The acidification of sodium silicate from coal fly ash with $1 \mathrm{M} \mathrm{HCl}$ via sol-gel process produced SG. It was calcined at $550{ }^{\circ} \mathrm{C}$ under air condition. The SG synthesis was validated by characterization of functional groups using FTIR (Figure 2). The peaks featured the functional groups of $\mathrm{SiO}_{2}$. Peaks 1,2 , and 3 from all samples can be seen at wavelengths of 465; 700 ; and $1,085 \mathrm{~cm}^{-1}$ showing sequential bending, symmetrical stretching, and asymmetrical stretching on inter tetrahedral oxygen atom $\mathrm{Si}$ 
-O- $\mathrm{Si}$ (siloxane) as the main structure of $\mathrm{SiO}_{2}$ [21]. In addition, the peak at wavelength 1,630 $\mathrm{cm}^{-1}$ (peak 4) and a broad peak at $3,440 \mathrm{~cm}^{-1}$ (peak 7) showed consecutively the characteristic of bending and stretching of $-\mathrm{OH}$ attached to the $\mathrm{SiO}_{2}$ frameworks to become silanol group (Si-OH). The differences in peak intensity of the silanol and siloxane structures on fly ash (Figure 2a) are lower than both on the silica gel (Figure 2b) reflecting the increase of purity silica content. Aside from that, the impurities were successfully removed from the $\mathrm{SiO}_{2}$ structure. It was confirmed by X-ray diffractogram.

The difference of the crystallinity pattern of fly ash and silica gels was exhibited in Figure 3 . The peaks of fly ash were at angle $2 \theta$ of 27 , 31,36 , and $44^{\circ}$ with low intensity. Those peaks do not appear on the silica gels implying that the impurities in the FA was already successfully separated and left $\mathrm{SiO}_{2}$ which is the main

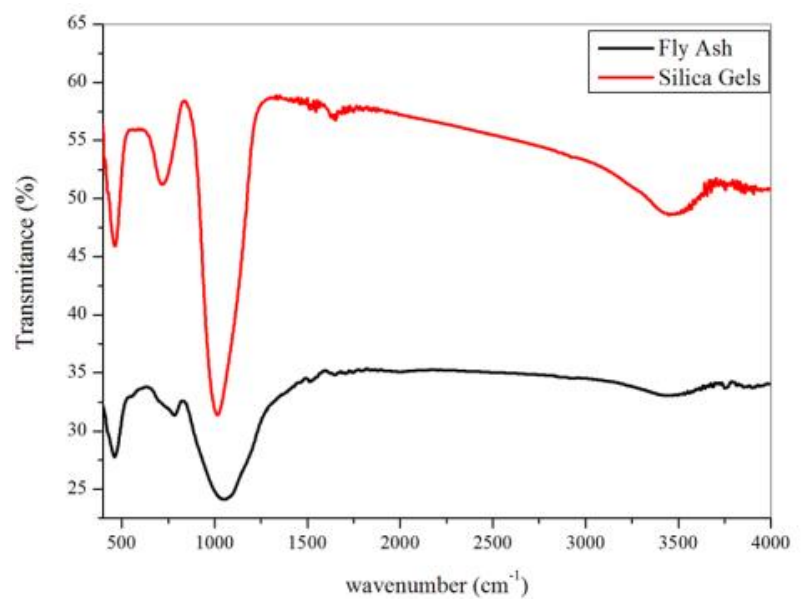

Figure 2. FT-IR spectra of materials

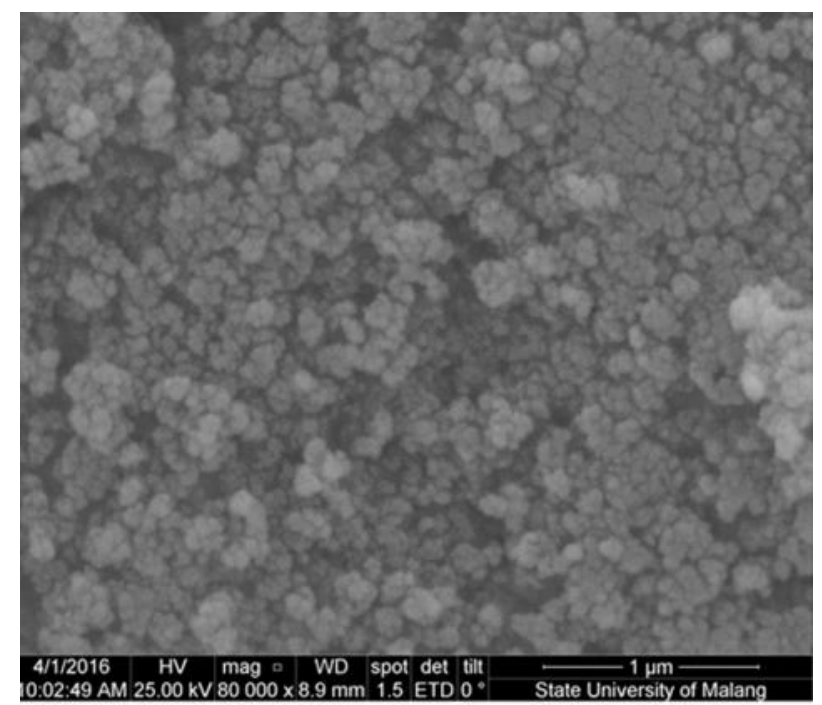

Figure 4. The surface morphology of silica gels part of silica gels framework. While, widening shape of silica gels peaks at the angle $2 \theta$ of 10 and $25^{\circ}$, which resembles a camel's hump, indicates the structure of silica gels framework have irregular shapes (amorphous).

The surface morphology shown in Figure 4 shows that the material SG with 80,000 times magnification has a nanoparticle size. It was known based on a comparison of particle size is much smaller than the bar lines worth $1 \mu \mathrm{m}$. Furthermore, the characterization of surface area, pore diameter, and volume using adsorption-desorption isothermal $\mathrm{N}_{2}$ was shown in Figure 5. The surface area silica gels were $25.977 \mathrm{~m}^{2}$. $\mathrm{g}^{-1}$ which were calculated by isothermal BET equation from adsorption-desorption $\mathrm{N}_{2}$. Isothermal adsorption curve followed the classification by IUPAC type II with no hysteresis loop that showed nonporous material [22]. It was confirmed by calculations using

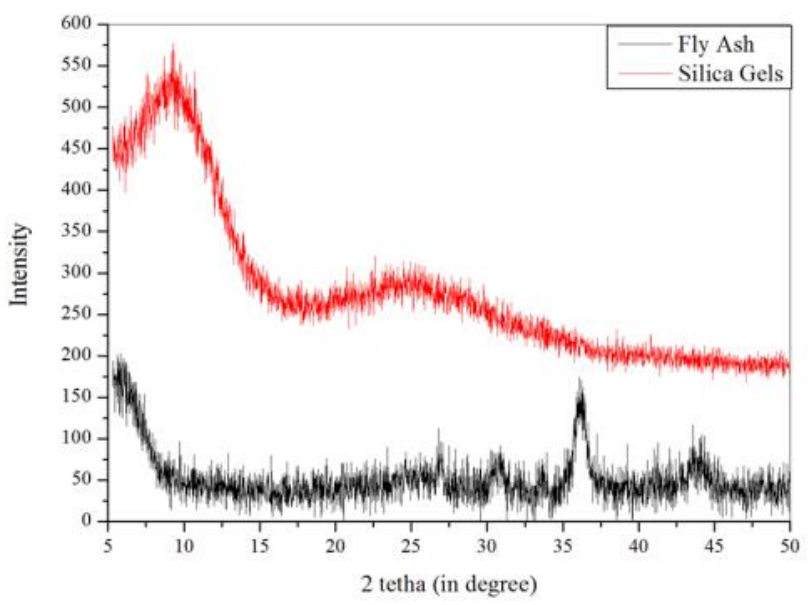

Figure 3. The X-Ray diffractogram of materials

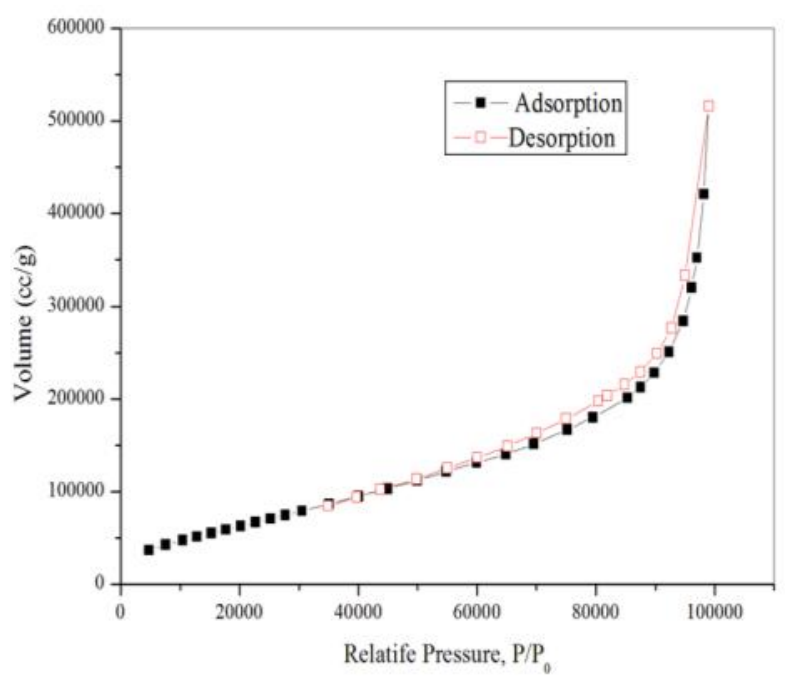

Figure 5. Isothermal adsorption-desorption $\mathrm{N}_{2}$ of silica gels 
BJH equation to determine the pore size and volume of silica gels of $1.528 \mathrm{~nm}$ and $7.97 \times 10^{-2}$ cc.g-1, respectively. The pore size with the size of $1.528 \mathrm{~nm}$ indicates microporous form. Thus, the absence of hysteresis loops on isothermal desorption curve and pore size calculation indicated that the silica gels were nonporous. This finding support with the surface area of silica gels, the smaller pore size was also getting smaller of surface area.

\subsection{Isothermal adsorption}

The determination of the methylene blue concentration using UV-Vis spectrophotometer was at a wavenumber of $664 \mathrm{~nm}$. The sorption capacity of silica gels against various concentrations of methylene blue is presented in Figure 6. The graph shows the equilibrium concentration versus the absorbed concentration of methylene blue. The adsorption capacity of silica gels and fly ash increased with the higher concentration of methylene blue ranging from 5 to $150 \mathrm{mg} . \mathrm{L}^{-1}$. A constant sorption started after $200 \mathrm{mg} . \mathrm{L}^{-1}$ concentration of $\mathrm{MB}$, indicating that the active group of silica gels and fly ash were saturated and unable to absorb methylene blue. Thus, the optimum sorption capacity of silica gels and fly ash against MB was at the concentration $200 \mathrm{mg} . \mathrm{L}^{-1}$. This finding was sup-

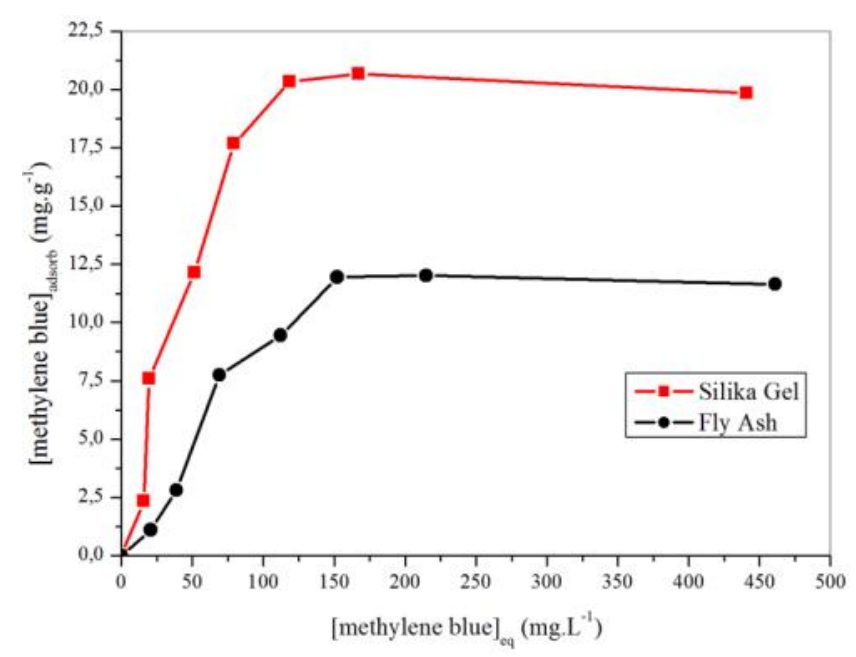

Figure 6. The adsorption isotherm materials on various methylene blue concentration ported by the previous result from FTIR Analysis. The higher difference of FTIR peak intensity shows the ability to adsorb more MB by $\Pi-\Pi$ interactions of siloxane framework, and by electrostatic interactions of silanol groups [21]. In addition, the purification of $\mathrm{SiO}_{2}$ from $\mathrm{FA}$ to be SG by eliminating the metal oxide is to increase the pore volume and to optimally diffuse MB.

The sorption capacity of the methylene blue by SG and fly ash were determined in order to perform data modeling in Langmuir $(L)$ and Freundlich $(F)$ models. The measurement parameters were adsorption capacity $\left(q_{m}\right)$, adsorption equilibrium constant $(K)$ and sorption affinity ( $n$ ) (Table 1). The isotherm models determined by the value of the coefficient correlation that most be close to 1 . Isotherms adsorption of methylene blue onto silica gels and fly ash followed the Langmuir model with the coefficient correlation linearity is closer to 1 than Freundlich model (Figure 7 and Figure 8). Thus, the adsorption properties of both adsorbates were only formed a single layer on the material surface [20]. This is supported by leveled adsorption capacity after $200 \mathrm{mg} . \mathrm{L}^{-1}$ shown in Figure 6. The Table 1 shows the adsorption capacity of silica gels and fly ash were 23.310 and $14.327 \mathrm{mg} \cdot \mathrm{g}^{-1}$, respectively. These data depicted that the removal of impurities in fly ash increased adsorption capacity by 62.70 $\%$. Compared to the study by Woolard et al. [15], the adsorption capacity of MB by the amorphous SG at room temperature was 22.66 mg.g-1, this present study SG from FA can be classified as a good potential adsorbent.

In addition, the adsorption of methylene blue using various adsorbents was reviewed by Rafatulloh et al. [11]. The adsorbents were classified into carbons, natural materials, bioadsorbents, agricultural solid wastes, and Industrial solid waste. The results comparison on adsorption capacities of $\mathrm{MB}$ with various adsorbents reported in Table 2 . This review described that carbon had the highest adsorption capacity of MB. It has giant frameworks of C-C that caused the high surface area and possibilities to make п-п electron donor-acceptor interaction and electrostatic attraction [24].

Table 1. Isothermal adsorption parameters of methylene blue

\begin{tabular}{lcccccc}
\hline \multirow{2}{*}{ Adsorbent } & \multicolumn{3}{c}{ Langmuir } & \multicolumn{3}{c}{ Freundlich } \\
\cline { 2 - 7 } & $q_{e}\left(\mathrm{mg} \cdot \mathrm{g}^{-1}\right)$ & $K_{L}\left(\mathrm{~L} \cdot \mathrm{mg}^{-1}\right)$ & $\mathrm{R}^{2}$ & $K_{F}\left({\left.\mathrm{~L} . g^{-1}\right)}^{2}\right.$ & $n_{F}$ & $\mathrm{R}^{2}$ \\
\hline Fly ash & 14.327 & 0.423 & 0.945 & 7.880 & 1.875 & 0.796 \\
Silica gels & 23.310 & 0.604 & 0.956 & 62.953 & 1.765 & 0.7001 \\
\hline
\end{tabular}


However, agricultural solid waste and bioadsorbent material also exhibit the good potential to remove the $\mathrm{MB}$, but not much higher than carbon. Many functional groups on their structure act as the site for electrostatic interaction between them. It can be concluded that the key point of adsorption capacity is the level surface area, followed by the active site of the materials. Therefore, the adsorption capacity of SG can be increased by modifying to be nanoparticles or adding the amount of the active site on the surface. Moritz et al. [25] used APTESmodified siliceous matrices to remove the pollutant 2,4-dichlorophenoxyacetic acid (2,4-D) with $\sim 280 \mathrm{mg} / \mathrm{g}$.

\subsection{The kinetics adsorption}

The influence of adsorption time was carried out by interacting methylene blue with the concentration of $200 \mathrm{mg} . \mathrm{L}^{-1}$ and adsorbent (fly ash and silica gels) using a variation of the concen-

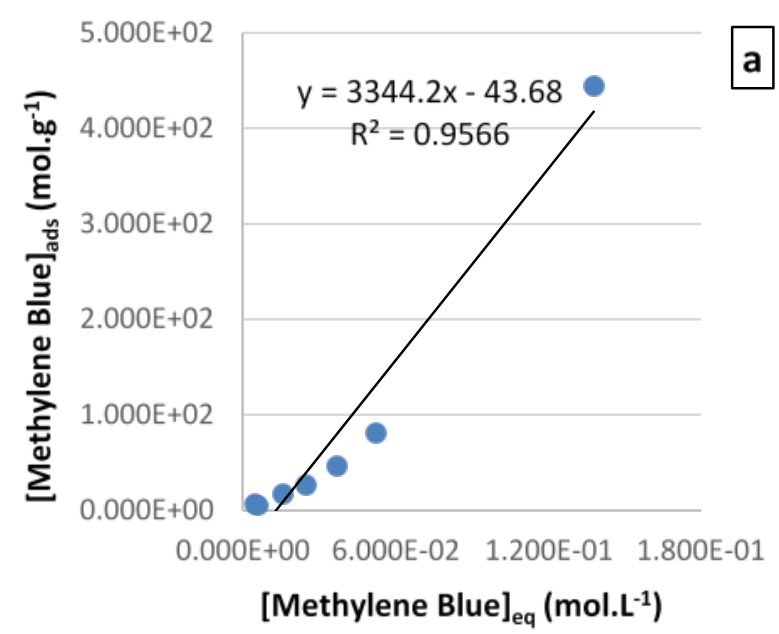

tration of $15,30,45,60$, and 90 minutes. The adsorbed concentration of the methylene blue in the adsorbent material is shown in Figure 9.

The isotherm adsorption methylene blue with interaction time variation of the FA and SG can be calculated using the multiple approaches of rate kinetics modeling such as pseudo-first-order, pseudo-second-order, Intraparticle and Elovich Equation Diffusion. The parameters were calculated based on the equation shown in Table 3 which shows that among the four equations in the determination of adsorption kinetics fly ash and silica gels to methylene blue that have sorption a correlation coefficient approach 1 . The kinetics models appropriated with the pseudo-second-order models for silica gels and fly ash based on the coefficient correlation consecutively of 0.968 and 0.995. Adsorption kinetics pseudo-secondorder showed that the relationship between the adsorbent and adsorbate influence each other

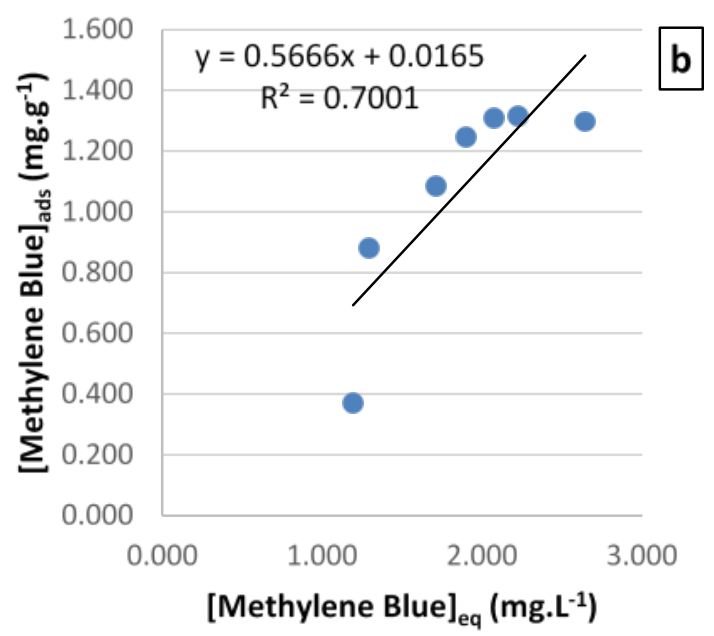

Figure 7. Isothermal adsorption methylene blue on silica gels using models: a) Langmuir; b) Freundlich
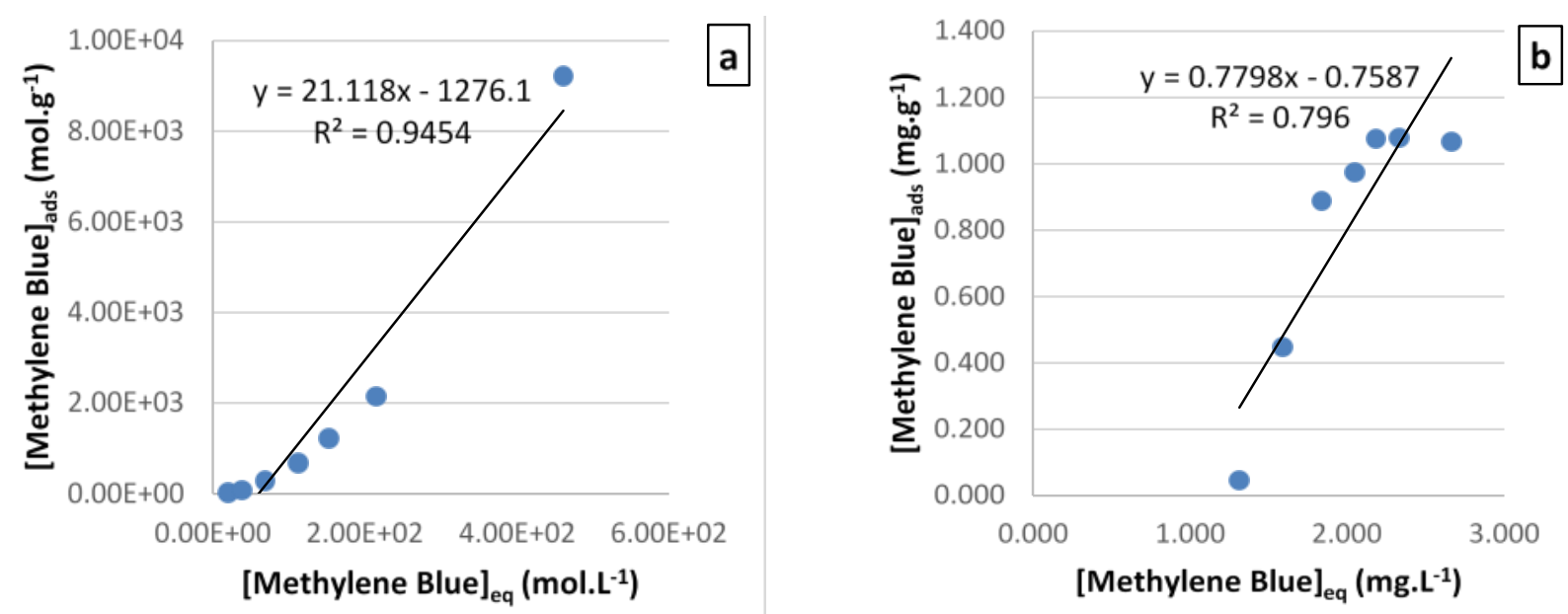

Figure 8. Isothermal adsorption methylene blue on fly ash using models: a) Langmuir; b) Freundlich 
Table 2. Previous adsorption capacity of methylene blue onto various adsorbent

\begin{tabular}{lll}
\hline Adsorbents & $q_{\max }\left(\mathrm{mg} \cdot \mathrm{g}^{-1}\right)$ & References \\
\hline Carbon & & \\
Activated carbon from Rattan sawdust & 294.12 & {$[26]$} \\
Fiber carbon & 225.64 & {$[27]$} \\
Carbon nanotube & 46.20 & {$[28]$} \\
$\quad$ Graphene Oxide & $1.94 ; 243.90$ & {$[24,29]$} \\
Natural Materials & & \\
Bentonite & 173 & {$[30]$} \\
Amorphous silica & 23.31 & This Study \\
Amorphous silica & 22.66 & {$[15]$} \\
Raw Kaolinite & 13.99 & {$[31]$} \\
Glass Wool & 2.24 & {$[32]$} \\
Bioadsorbents & & \\
Mediterranean green alga (Enteromorpha spp.) & 274 & {$[33]$} \\
Algal Waste & 104 & {$[34]$} \\
Red seaweed (Gracilaria corticata) & 95.41 & {$[35]$} \\
Dead (Streptomyces rimosus) & 7.95 & {$[36]$} \\
Marine seaweed (Caulerpa racemosa var. cyl- & 3.42 & {$[37]$} \\
indracea) & & \\
Agricultural Solid Wastes & & \\
Peanut hull & 68.03 & {$[38]$} \\
Yellow passion fruit waste & 44.70 & {$[39]$} \\
Date palm leaves & 43,10 & {$[40]$} \\
Rice husk & 40.58 & {$[41]$} \\
Wheat Shells & 16.34 & {$[42]$} \\
Industrial Solid Wastes & & {$[13]$} \\
Coal fly ash, 0.01 NaCl & 16.60 & This Study \\
Coal fly ash & 14,33 & {$[13]$} \\
Coal fly ash, no NaCl & 12.70 & {$[15]$} \\
Red Mud Alumina Industry & 2.49 & \\
Coal ash & 1.11 & \\
\hline & & \\
\end{tabular}

Table 3. The kinetics adsorption of methylene blue parameters onto fly ash and silica gels

\begin{tabular}{|c|c|c|c|}
\hline \multirow{2}{*}{\multicolumn{2}{|c|}{ Parameter }} & \multicolumn{2}{|c|}{ Materials } \\
\hline & & Silica Gels & Fly Ash \\
\hline \multirow{3}{*}{ Pseudo First Order } & $q_{e}\left(\mathrm{mg} \cdot \mathrm{g}^{-1}\right)$ & $3.18 \times 10^{-4}$ & $6.41 \times 10^{-4}$ \\
\hline & $k_{1}\left(\min ^{-1}\right)$ & 0.019 & 0.012 \\
\hline & $\mathrm{R}^{2}$ & 0.899 & 0.904 \\
\hline \multirow{3}{*}{ Pseudo Second Order } & $q_{e}\left(\mathrm{mg} \cdot \mathrm{g}^{-1}\right)$ & 24.450 & 21.645 \\
\hline & $k_{2}\left(\mathrm{mg} \cdot \mathrm{g}^{-1} \cdot \mathrm{min}^{-1}\right)$ & $1,346.176$ & 397.309 \\
\hline & $\mathrm{R}^{2}$ & 0.995 & 0.968 \\
\hline \multirow{3}{*}{ Interparticle Diffusion } & $k_{p}\left(\mathrm{mg} \cdot \mathrm{g}^{-1} \cdot \mathrm{min}^{-1 / 2}\right)$ & 1.887 & 1.836 \\
\hline & $C\left(\mathrm{mg} \cdot \mathrm{g}^{-1}\right)$ & 5.876 & 0.398 \\
\hline & $\mathrm{R}^{2}$ & 0.913 & 0.949 \\
\hline \multirow{3}{*}{ Elovich Equation } & $a\left(\mathrm{mg} \cdot \mathrm{g}^{-1} \cdot \mathrm{min}^{-1}\right)$ & 5.473 & 11.774 \\
\hline & $\beta\left(\mathrm{g} \cdot \mathrm{mg}^{-1}\right)$ & 0.203 & 0.213 \\
\hline & $\mathrm{R}^{2}$ & 0.9804 & 0.942 \\
\hline
\end{tabular}


in the process of adsorption. The adsorption rate of silica gels was 3.37 times faster than the adsorption rate on the FA.

\section{Conclusions}

In summary, the silica gels have been successfully synthesized via sol-gel method from sodium silicate which is isolated from the fly ash. Both fly ash and silica gels can remove methylene blue as a cationic dye in aqueous solution. The isotherm adsorption followed Langmuir's models that showed monolayer adsorption and electrostatic interaction between methylene blue and adsorbents. Compare with fly ash, silica gels shows higher adsorption capacity. The kinetics of adsorption followed the pseudo-second-order model which proves both the adsorbent and adsorbate influential in the adsorption process.

\section{References}

[1] Adam, F., Nelson, J., Khanam, Z., Thankappan, R., Asri, M., Nawi, M. (2013). Applied Surface Science Utilization of Tin and Titanium Incorporated Rice Husk Silica Nanocomposite as Photocatalyst and Adsorbent for The Removal of Methylene Blue in Aqueous Medium. Applied Surface Science, 264: 718726.

[2] Amran, M., Salleh, M., Khalid, D., Azlina, W., Abdul, W., Idris, A. (2011). Cationic and Anionic Dye Adsorption by Agricultural Solid Wastes: A Comprehensive Review. Desalination, 280(1-3): 1-13.

[3] Ma, G., Zhu, Y., Zhang, Z., Li, L. (2014). Preparation and Characterization of MultiWalled Carbon Nanotube/ $/ \mathrm{TiO}_{2}$ Composites:

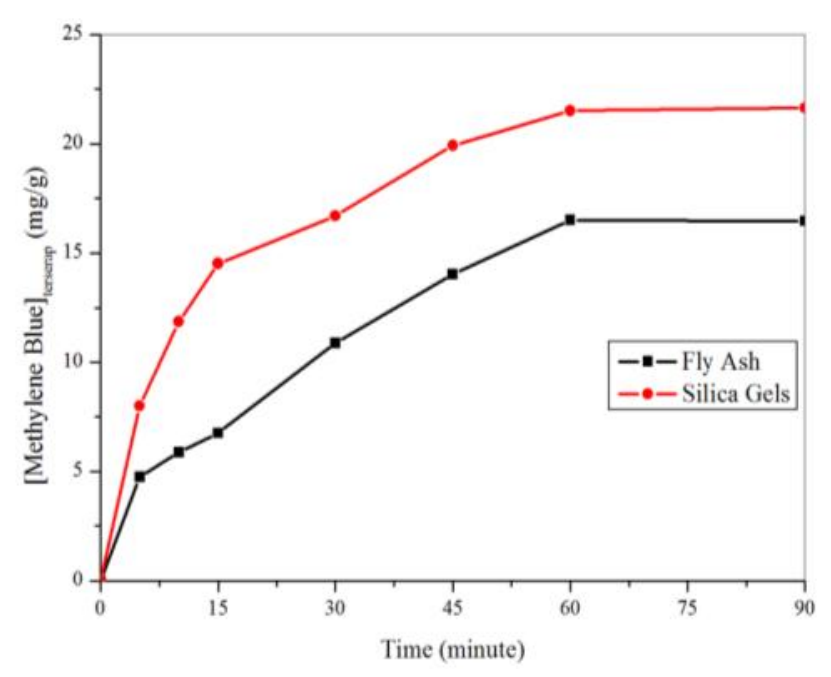

Figure 9. The isothermal adsorption of methylene blue on various time interaction
Decontamination Organic Pollutant in Water. Applied Surface Science, 313: 817-822.

[4] Chen, Q., He, Q., Lv, M., Xu, Y., Yang, H., Liu, X., Wei, F. (2015). Applied Surface Science Selective Adsorption of Cationic Dyes by UiO-66- $\mathrm{NH}_{2}$. Applied Surface Science, 327: 77-85.

[5] Kim, H., Kang, S., Park, S., Seok, H. (2015). Chemistry Adsorption Isotherms and Kinetics of Cationic and Anionic Dyes on ThreeDimensional Reduced Graphene Oxide Macrostructure. Journal of Industrial and Engineering Chemistry, 21: 1191-1196.

[6] Solmaz, K.S.A., Birgul, A., Ustun, G.E., Yonar, T. (2006). Colour and COD Removal From Textile Effluent by Coagulation and Advanced Oxidation Processes. Coloration Technology, 122: 102-109.

[7] Barka, N., Assabbane, A., Nounah, A., Ichou, A,Y. (2008). Photocatalytic Degradation of Indigo Carmine in Aqueous Solution by $\mathrm{TiO}_{2}-$ Coated Non-Woven Fibres. Journal of Hazardous Materials, 152: 1054-1059.

[8] Wangpradit, R., Chitprasert, P. (2014). Chitosan-Coated Lentinus Polychrous Lev.: Integrated Biosorption and Biodegradation Systems for Decolorization of Anionic Reactive Dyes. International Biodeterioration \& Biodegradation, 93: 168-176.

[9] Chen, X., Zhao, Y., Moutinho, J., Shao, J., Zydney, A.L., He, Y. (2015). Recovery of Small dye Molecules From Aqueous Solutions Using Charged Ultrafiltration Membranes. Journal of Hazardous Materials, 284: 58-64.

[10] Wang, T., Kailasam, K., Xiao, P., Chen, G., Chen, L., Wang, L., Li, J., Zhu, J. (2014). Adsorption Removal of organic Dyes on Covalent Triazine Framework (CTF). Microporous and Mesoporous Materials, 187: 63-70.

[11] Rafatullah, M., Sulaiman, O., Hashim, R., Ahmad, A. (2010). Adsorption of Methylene Blue on Low-Cost Adsorbents: A review. Journal of Hazardous Materials, 177(1-3): 7080.

[12] Adak, D., Sarkar, M., Mandal, S. (2014). Effect of Nano-Silica on Strength and Durability of Fly Ash Based Geopolymer Mortar. Construction and Building Materials, 70: 453-459.

[13] Wang, S., Ma, Q., Zhu, Z.H. (2008). Characteristics of Coal Fly Ash and Adsorption Application. Fuel, 87: 3469-3473.

[14] Janos, P., Buchtova, H., Milena, R. (2003). Sorption of Dyes from Aqueous Solutions onto Fly Ash. Water Research, 37: 4938-4944. 
[15] Woolard, C.D., Strong, J., Erasmus, C.R. (2002). Evaluation of the Use of Modified Coal Ash as a Potential Sorbent for Organic Waste Streams. Applied Geochemistry, 17: 11591164.

[16] Kalapathy, U., Proctor, A., Shultz, J. (2000). A Simple Method For Production Of Pure Silica From Rice Hull Ash. Bioresource Technology, 73: 257-262.

[17] Affandi, S., Setyawan, H., Winardi, S., Purwanto, A., Balgis, R. (2009). A Facile Method for Production of High-Purity Silica Xerogels from Bagasse Ash. Advanced Powder Technology, 20(5): 468-472.

[18] Selvaggi, R., Tarpani, L., Santuari, A., Giovagnoli, S., Latterini, L. (2015). Silica Nanoparticles Assisted Photodegradation of Acridine Orange in Aqueous Suspensions. Applied Catalysis B, Environmental, 168-169: 363-369.

[19] Goscianska, J., Olejnik, A., Pietrzak, R. (2013). Adsorption of L-phenylalanine onto Mesoporous Silica. Materials Chemistry and Physics, 142(2-3): 586-593.

[20] Alver, E., Metin, Ü. (2012). Anionic Dye Removal from Aqueous Solutions Using Modified Zeolite: Adsorption Kinetics and Isotherm Studies. Chemical Engineering Journal, 200202: 59-67.

[21] Errais, E., Duplay, J., Darragi, F., Rabet, I. M., Aubert, A., Huber, F., \& Morvan, G. (2011). Efficient Anionic Dye Adsorption on Natural Untreated Clay: Kinetic Study and Thermodynamic Parameters. Desalination, 275(1-3): 74-81.

[22] Ho, Y.S., Mckay, G. (1999). Pseudo-second Order Model for Sorption Processes. Process Biochemistry, 34: 451-465.

[23] Wu, F., Tseng, R., Juang, R. (2009). Initial Behavior of Intraparticle Diffusion Model Used in The Description of Adsorption Kinetics. Chemical Engineering Journal, 153: 1-8.

[24] Li, Y., Du, Q., Liu, T., Peng, X., Wang, J., Sun, J., Wang, Y., Wu, S., Wang, Z., Xia, Y., Xia, L. (2013). Comparative Study of Methylene Blue Dye Adsorption onto Activated Carbon, Graphene Oxide, and Carbon Nanotubes. Chemical Engineering Research and Design, 91: 361-368.

[25] Moritz, M., Geszke-Moritz, M. (2014). Application of Nanoporous Silicas as Adsorbents for Chlorinated Aromatic Compounds. A Comparative Study. Materials Science and Engineering $C$, 41: 42-51.

[26] Hameed, B.H., Ahmad, A.L., Latiff, K.N.A. (2007). Adsorption of Basic Dye (Methylene Blue) onto Activated Carbon Prepared From
Rattan Sawdust. Dyes and Pigments, 75: 143149.

[27] Senthilkumaar, S., Varadarajan, P.R., Porkodi, K., Subbhuraam, C.V. (2005). Adsorption of Methylene Blue onto Jute Fiber Carbon: Kinetics and Equilibrium Studies. Journal of Colloid and Interface Science, 284: 78-82.

[28] Yao, Y., Xu, F., Chen, M., Xu, Z., Zhu, Z. (2010). Bioresource Technology Adsorption Behavior of Methylene Blue on Carbon Nanotubes. Bioresource Technology, 101(9): 30403046.

[29] Zhang, W., Zhou, C., Zhou, W., Lei, A., Zhang, Q., Wan, Q., Zou, B. (2011). Fast and Considerable Adsorption of Methylene Blue Dye onto Graphene Oxide. Bulletine Environmental Cantaminant Toxicology, 87: 86-90.

[30] Hong, S., Wen, C., He, J., Gan, F., Ho, Y. (2009). Adsorption Thermodynamics of Methylene Blue onto Bentonite. Journal of Hazardous Materials, 167, 630-633.

[31] Ghosh, D., Bhattacharyya, K.G. (2002). Adsorption of Methylene Blue on Kaolinite. Applied Clay Science, 20: 295-300.

[32] Chakrabarti, S., Dutta, B.K. (2005). On The Adsorption and Diffusion of Methylene Blue in Glass Fibers. Journal of Colloid and Interface Science, 286: 807-811.

[33] Ncibi, M.C., Hamissa, A.M. Ben, Fathallah, A., Kortas, M.H., Baklouti, T., Mahjoub, B., Seffen, M. (2009). Biosorptive Uptake of Methylene Blue Using Mediterranean Green Alga Enteromorpha spp. Journal of Hazardous Materials, 170: 1050-1055.

[34] Vilar, J.P., Botelho, M.S., Boaventura, R.A.R. (2007). Methylene Blue Adsorption by Algal Biomass Based Materials: Biosorbents characterization and process behaviour. Journal of Hazardous Materials, 147: 120-132.

[35] Vijayaraghavan, J., Pushpa, T.B., Basha, S.J.S., Jegan, J., Pushpa, T.B., Basha, S.J.S. (2015). Isotherm, Kinetics and Mechanistic Studies of Methylene Blue Biosorption onto Red Seaweed Gracilaria Corticata. Desalination and Water Treatment, 1-9.

[36] Nacera, Y., Aicha, B. (2006). Equilibrium and Kinetic Modelling of Methylene Blue Biosorption by Pretreated Dead Streptomyces Rimosus: Effect of temperature. Chemical Engineering Journal, 119: 121-125.

[37] Cengiz, S., Cavas, L. (2008). Removal of Methylene Blue by Invasive Marine Seaweed: Caulerpa Racemosa var. Cylindracea. Bioresource Technology, 99: 2357-2363. 
[38] Gong, R., Li, M., Yang, C., Sun, Y., Chen, J. (2005). Removal of Cationic Dyes From Aqueous Solution by Adsorption on Peanut Hull. Journal of Hazardous Materials B, 121: 247250.

[39] Pavan, F.A., Lima, E.C., Dias, S.L.P., Mazzocato, A.C. (2008). Methylene Blue Biosorption from aqueous Solutions by Yellow Passion Fruit Waste. Journal of Hazardous Materials, 150: 703-712.

[40] Gouamid, M., Ouahrani, M.R., Bensaci, M.B. (2013). Adsorption Equilibrium, Kinetics and Thermodynamics of Methylene Blue From Aqueous Solutions Using Date Palm Leaves. Energy Procedia, 36: 898-907.
[41] Vadivelan, V., Kumar, K.V. (2005). Equilibrium, Kinetics, Mechanism, and Process Design for The Sorption of Methylene Blue onto Rice Husk. Journal of Colloid and Interface Science, 286: 90-100.

[42] Bulut, Y., Aydin, H. (2006). A Kinetics and Thermodynamics Study of Methylene Blue Adsorption on Wheat Shells. Desalination, 194: 259-267.

[43] Wang, S., Boyjoo, Y., Choueib, A., Zhu, Z.H. (2005). Removal of Dyes from Aqueous Solution Using Fly Ash and Red Mud. Water Research, 39: 129-138.

Selected and Revised Papers from The 2nd International Seminar on Chemistry (ISoC 2016) (Surabaya, 26-27 July 2016) (http://chem.its.ac.id/isoc-2016/) after Peer-reviewed by Scientific Committee of ISoC 2016 and Peer-Reviewers of BCREC journal 